\title{
The Association Between Residual Neuromuscular Blockade (RNMB) and Critical Respiratory Events: A Prospective Cohort Study
}

Faraj Alenezi ( $\sim$ farajalenezi@gmail.com )

King Saud bin Abdulaziz University for Health Sciences https://orcid.org/0000-0001-8596-1983

Khalid Alnababtah

Birmingham City University

Mohammed Alqahtani

King Saud bin Abdulaziz University for Health Sciences

Mohammed Al Harbi

King Saud bin Abdulaziz University for Health Sciences

\section{Research}

Keywords: Neuromuscular blocking drugs, Residual neuromuscular blockade, Critical respiratory events

Posted Date: May 1st, 2020

DOI: https://doi.org/10.21203/rs.3.rs-24919/v1

License: (9) This work is licensed under a Creative Commons Attribution 4.0 International License.

Read Full License

Version of Record: A version of this preprint was published at Perioperative Medicine on May 4th, 2021.

See the published version at https://doi.org/10.1186/s13741-021-00183-7. 


\section{Abstract}

Background: Inadequate neuromuscular recovery might impair pulmonary function among adult patients who undergo general anaesthesia and might thus contribute to critical respiratory events in the postanaesthesia care unit (PACU). The aim of this study to investigate whether critical respiratory events (CREs) that described in a modified Murphy's criteria are significantly associated with residual neuromuscular blockade (RNMB).

Method: A prospective cohort study from January to March 2017 from a tertiary hospital from Saudi Arabia for thirty adult patients over 18 years old scheduled for elective surgery under general anaesthesia with neuromuscular blocking drugs (NMBDs) were enrolled in the study. The Mann-Whitney U tests, ChiSquare tests and Independent-Samples T tests were used. The Train-of-four (TOF) ratios were measured upon arrival in the PACU by using Acceleromyography with TOF-Scan. Subjects' demographics, perioperative data, and the occurrence of postoperative CREs in the PACU were recorded.

Results: 26 (86.7\%) patients out of thirty in the study has received Rocuronium as NMBDs while Neostigmine as a reversal drug with only $23(76.7 \%)$. The incidence of RNMB (TOF ratio $<0.9$ ) was in 16 patients (53.3\%). The incidence of RNMB was significantly higher in female patients $(p=0.033)$, in patients who had not undergone quantitative neuromuscular monitoring before extubation $(p=0.046)$ and in patients with shorter duration of surgery $(p=0.001)$. Postoperative CREs occurred in twenty patients $(66.7 \%)$, and there were significantly more of these CREs among patients with RNMB $(P=0.001)$. In addition, a statistically significant difference was observed in the occurrence of CREs according to body mass index $(P=0.047)$.

Conclusion: This research showed that RNMB is a significant contributing factor to the development of critical respiratory events during PACU stay. Therefore, optimal antagonism of neuromuscular blockade and routine quantitative neuromuscular monitoring are recommended to reduce the incidence of RNMB.

\section{Introduction}

Many patients are at high risk of adverse events during the early postoperative period, which might be caused by anaesthetic or surgical procedures. These adverse events include cardiovascular or respiratory complications (Buhre and Rossaint 2003). Therefore, areas known as post-anaesthesia care units (PACU) have been established in many hospitals worldwide, which are intended to provide specialised care and minimise morbidity and mortality through the timely detection or prevention of adverse events (Kiekkas et al. 2014). In clinical practice, neuromuscular blocking drugs (NMBDs) are commonly used by anaesthesiologists during general anaesthesia in order to maintain optimal surgical conditions by maintaining the deep muscle relaxation and to facilitate tracheal intubation (Claudius et al. 2009). However, their effects might continue after extubation: this is called residual neuromuscular blockade (RNMB). According to Murphy et al. (2008a), between $33 \%$ and $64 \%$ of patients have evidence of incomplete neuromuscular recovery or RNMB during their stay in the PACU, despite the use of techniques 
proven to limit the degree of RNMB, such as reversal drugs. The incidence of RNMB ranges between $26 \%$ and $88 \%$, based on the type of NMBDs, reversal drugs, or neuromuscular monitoring used (Cammu et al. 2012; Fortier et al. 2015). The RNMB can be reliably detected through the use of neuromuscular monitoring such as Train-of-Four (TOF) monitoring, which is according to Murphy et al. (2011) is considered one of the most commonly used approaches in clinical practice. This method however, is used during recovery from the application of NMBDs to objectively decide how well a patient's muscles are able to function, which includes the application of electrical stimulation to nerves and the recording of muscle responses, called the TOF ratio (Butterworth 2013). The TOF ratio when it is $\geq 0.90$ is considered the gold standard for defining adequate neuromuscular recovery, whereas RNMB is present when the TOF ratio < 0.90 (Murphy 2006). Accordingly, The RNMB might place patients at an increased risk of critical respiratory events (CREs) in the PACU. Evidence from observational studies suggests that TOF ratios when it is less than 0.90 are usually associated with the incidence of CREs that include inadequate recovery of pulmonary function, upper airway obstruction, impaired pharyngeal reflexes, decreased muscle coordination, impaired hypoxic ventilatory response and increased risk of aspiration (Cammu et al. 2012; Herbstreit et al. 2009; Murphy et al. 2008a).

To date, the incidence of RNMB and its association with CREs during the PACU stay has not been investigated in Saudi Arabia. In addition, the issue of whether or not neuromuscular monitoring is usually used has not been investigated. This study aims to determine the incidence of RNMB and CREs in the PACU among patients who have undergone general anaesthesia.

\section{Methods}

\section{Study Design}

A pilot prospective cohort design was used in this study which is part of a student project at Cardiff University. The study was conducted in the post anaesthesia care unit (PACU) at the National Guard Hospital, King Abdulaziz Medical City in Riyadh, Saudi Arabia. The study has been approved by the King Abdullah International Medical Research Centre (KAIMRC) at King Abdulaziz Medical City. Informed written consent was obtained from all patients before entry into the study. Participants were enrolled between $21^{\text {st }}$ January 2017 and $21^{\text {st }}$ March 2017.

A total of 120 patients were screened for their eligibility by anaesthetists and the researcher based on the inclusion and exclusion criteria at a pre-anaesthesia clinic over a period of 4 weeks (Table 1). A total of 30 patients, consisting of 17 males and 13 females, were recruited for analysis.

The following baseline demographic variables were collected: age, gender, height, weight, body mass index (BMI), Operative variables collected included type and duration of the operation. The anaesthesiologists were blinded to the patients' participation in the study and the NMBDs were supervised according to the standards of patient care in PACU and whether these patients required oxygen following their extuabation in operating theatre. 
On arrival at the PACU, type and dose of neuromuscular blockade drugs (NMBDs), reversal drugs and duration of surgery are recorded by qualified nurses in PACU. They also measured the following postoperative outcomes: peripheral oxygen saturation (SpO2), respiratory rate and TOF ratio during the first thirty minutes of arrival into the PACU in which all of them were obtained by the researcher. TOF ratio was obtained via acceleromyography (quantitative neuromuscular monitoring) at the adductor pollicis of the thumb (TOF-Scan ${ }^{T M}$, IdMed, Marseille, France). When the patients experienced any of CREs based on the modified Murphy's criteria within the first thirty minutes in admission to the PACU, the nurses have directly informed the researcher about these changes in the patients' condition as shown in (Table 2).

\section{Statistical Analysis}

All Statistical analysis for the current study was performed by using the Statistical Package for the Social Sciences (version 23.0). Categorical data were presented as percentages or frequencies and Chi-Square test was used for comparison. For non-normally distributed data, Mann-Whitney $\mathrm{U}$ test, median and interquartile range (IQR) were used, while the mean, standard deviation (SD) and Independent-Samples T tests were used if normally distributed. A p value of less than 0.05 was considered for the significance level.

\section{Results}

A total of 120 patients during the period of the study were assessed for their eligibility to participate based on the aforementioned inclusion and exclusion criteria and therefore, 30 patients out of 120 were included in the study. For those patients who had excluded; 19 with Chronic obstructive pulmonary disease (COPD), 22 with abdominal emergency surgery, and 49 undergone elective surgery that lasted more than four hours (240 minutes).

Demographic data of the population, surgical and anaesthesia details are summarized in Table 3. The median age of participants was 35 years. The majority of these participants were male (56.7\%), while female patients represented $43.3 \%$ of the sample. Based on Fortier et al. (2015) and Murphy et al. (2015), patients' age was categorized into two age groups: younger patients (age 18 to 50 years) and elderly patients (age $\geq 51$ years). More than half of the studied patients had ASA PS class II (56.7\%), followed by ASA PS class I (33.3\%). The majority of the cohort was undergoing general surgeries (43.3\%) and ENT surgeries (33.3\%), followed by urology surgeries (13.3\%). The most frequently used NMBD during the current study was rocuronium (86.7\%), while the most frequently used reversal drug was Neostigmine (76.7\%). The mean of BMI among the participants was $29.45 \pm 5.56 \mathrm{~kg} / \mathrm{m}^{2}$.

The incidence of RNMB (TOF ratio < 0.90 ) was 53.3\% (16/30). In comparing the preoperative variables among patients who had RNMB on PACU admission, the Chi-Square test clearly showed that there were no significant differences between the incidence of RNMB according to the age of patients (18-50 vs. $\geq$ 51 years) or ASA-PS Class, with $\mathrm{P}=0.0544$ and $\mathrm{P}=0.103$, respectively. The same test demonstrated that the incidence of the RNMB was significantly higher in female gender as shown in Figure 1 ( $76.9 \%$ vs. 
$35.3 \%, P=0.033)$, in patients who had not had neuromuscular monitoring before extubation $(66.7 \%$ vs. $22.2 \%, P=0.046)$, and in shorter duration of surgery $(81.8 \%$ vs. $21.4 \%, P=0.001)$. Independent-Samples $T$ tests demonstrated no significant differences in RNMB in relation to BMI $(P=0.294)$. In comparing patients who had RNMB upon arrival in the PACU with those who did not, the Mann-Whitney $U$ test demonstrated a significant relationship between the incidence of RNMB and both oxygen desaturation and respiratory rate, at $\mathrm{P}=0.034$ and $\mathrm{P}=0.025$, respectively.

Overall, $66.7 \%$ of patients who underwent elective surgeries under general anaesthesia experienced postoperative CREs, compared with $33.3 \%$ who did not (Table 5). The Mann-Whitney U test revealed that there was no significant difference in postoperative CREs in the PACU between age groups and groups with long vs. short surgery times. The median of the TOF ratio upon arrival in the PACU was 0.88 in patients with postoperative CREs. The Chi-Square test demonstrated that RNMB (TOF ratio $<0.90$ ) was more frequent among those participants with postoperative CREs ( $75 \%$ vs. $10 \%, P=0.001)$. The MannWhitney $U$ test demonstrated no significant association between patients' temperature and the incidence of CREs. The Independent-Samples $T$ tests showed a significant difference in postoperative CREs between the two BMl groups ( $31.23 \pm 6.1$ vs. $26.78 \pm 3.94, P=0.047)$.

A total of 20 patients (66.7\%) had CREs (Table 6). The most commonly CREs were observed among these patients as the following: signs of respiratory distress (50\%), mild-moderate hypoxemia (30\%), and upper airway obstruction (16.7\%). Other CREs observed were severe hypoxemia (13.3), upper airway weakness $(10 \%)$ and inability to breathe deeply $(6.7 \%)$. None of the patients had pulmonary aspiratory and none of them required re-intubation in the PACU stay.

\section{Discussion}

The aim of current study was to examine whether RNMB is significantly associated with postoperative CREs by determining the incidence of RNMB and postoperative CREs and the associated risk factors during the PACU stay in a tertiary hospital in Saudi Arabia. The incidence of RNMB in our cohort was $53.3 \%$ and postoperative CREs were observed among $66.7 \%$ of our cohort. The findings show that there was a statistically significant association between the incidence of RNMB and postoperative CREs (75\% vs $10 \%, P=0.001)$.

Based on the patients' demographic data and preoperative variables, which are presented in table 4, the results of the current study do not show any statistically significant relationships between patients' age, BMI and ASA-PS Class and the incidence of RNMB in the PACU ( $P=0.901, P=0.103, P=0.294$, respectively). These findings are consistent with the literature, which showed that age is not related to the incidence of RNMB (Fortier et al. 2015; Kaan et al. 2012; Murphy et al. 2013; Tsai et al. 2008). Justification for the agreement between the results of this study and the abovementioned studies regarding age and incidence of RNMB is that all authors recruited samples of similar ages (18 to 65 years). Fortier et al. (2015) examined the incidence of RNMB according to age, ASA-PS class and BMI and their results were consistent with those reported in the present study, with no statistically significant differences between 
the incidence of RNMB in relation to ASA-PS class or BMI (all P > 0.13). Murphy et al. (2013) also agreed with the previous findings and demonstrated that there were no significant differences in RNMB in relation to ASA-PS class. The similarity in the results might because both Fortier et al. (2015) and this study had almost the same ASA-PS class, as the majority of the patients in both samples had ASA-PS class II (52.7\% and $56.7 \%$, respectively). However, the lack of patients with higher ASA-PS class who might have serious systemic diseases among the participants in the current study might have influenced the results obtained. For instance, an observational study carried out by Aytac et al. (2016) found that the incidence of RNMB was significantly higher in patients with ASA-PS class III $(P<0.05)$.

However, on examining the literature furthermore, studies by Murphy et al. (2015) and Pietraszewski and Gaszyński (2013) reported associations between age and the incidence of RNMB and these findings demonstrated a disagreement with the findings of the current study. Pietraszewski and Gaszyński (2013) found that the incidence of RNMB was happening more $(P<0.05)$ with elderly $(44 \%)$ than in younger patients (20\%), and that was the same in Murphy et al. (2015) as the incidence of PRNB was $57.7 \%$ in elderly patients and $30.0 \%$ in younger patients $(P<0.001)$. However, these significant differences might be related to the age of enrolled patients which was over 70 years in both of these studies.

The impact of gender on the incidence of RNMB was demonstrated in the current study which shows that female patients were significantly more likely to experience RNMB in the PACU than males $(P=0.033)$ as shown in table 4. These findings are consistent with other studies conducted by Aytac et al. (2016), Pietraszewski and Gaszyński (2013), and Kaan et al. (2012). This could be to that women are more sensitive to rocuronium, the onset time of rocuronium is shorter in women and its effective period is prolonged (Xue et al, 1997 and Adamus et al., 2008). They also added that the variability of sensitivity and action duration of NMBDs between women and men is believed to be associated with physiological differences in body structures. Whilst, Aytac et al. (2016) also found that female patients undergoing anaesthesia of short duration are more likely to have RNMB in the PACU. Therefore, both Xue et al. (1997) and Adamus et al. (2008) suggest that the dose of rocuronium routinely used in females could be reduced.

Other significant findings in the current studies that the incidence of RNMB is significantly more frequent among patients for whom neuromuscular monitoring (acceleromyography) has not been used prior to extubation ( $P=0.046$ ). Several surveys conducted in different countries (Fuchs-Buder et al. 2003; Grayling and Sweeney 2007; Nava-Ocampo et al. 2002; Sorgenfrei et al. 2005) have reported similar to this, but they cannot be directly compared because they used different techniques for neuromuscular monitoring. The results of these surveys indicate that neuromuscular monitors were routinely used in only $10 \%$ of cases by clinicians in Germany, 43\% (Fuchs-Buder et al., 2003); in Denmark, 2\% (Grayling and Sweeney, 2007); in Mexico, 2\% (Nava-Ocampo et al., 2002) and in United Kingdom, 28\% (Sorgenfrei et al. 2005). Naguib et al. (2010) carried out a survey to compare the clinical attitudes and practices regarding neuromuscular management between anaesthesia consultants in Europe and the United States. The authors found that $9.4 \%$ of American anaesthesia consultants and 19.3\% European counterparts never used neuromuscular monitoring. Murphy et al. (2008b) examined the incidence of RNMB in the PACU 
among patients who were evaluated with quantitative acceleromyographic monitoring or conventional qualitative monitoring, and found that RNMB was more common in the conventional monitoring group $(30 \%)$ than that in the quantitative monitoring group $(4.5 \%)(p<0.001)$. The findings reported by Fortier et al. (2015) were most similar to those of the present study: they investigated the use of acceleromyography monitoring to determine the incidence and degree of postoperative RNMB (TOF ratio $<0.90$ ) upon arrival at the PACU. Also, similar to this study, most of the cases $(73.9 \%)$ used rocuronium and neostigmine for the reversal of NMBD. The results of this study show that without using acceleromyography monitoring, the incidence of RNMB upon arrival at the PACU was $56.5 \%$.

The findings of this study suggest that there was a significant difference in the incidence of RNMB in relation to the duration of surgery ( $<90$ minutes compared with $\geq 90$ minutes; $P=0.001$ ). On examining the literature, few studies have investigated the association between the incidence of RNMB and the duration of surgery. However, the result of this current study is consistent with the findings of an old study by McCaul et al. (2002) which examined the same variable an. McCaul et al. (2002) reported that patients with RNMB (TOF ratio $\leq 0.70$ ) at extubation had significantly shorter duration of surgery ( $59 \mathrm{vs.} 103$ minutes, $\mathrm{P}<0.001)$. Moreover, in a more recent study, Stewart et al. (2016) also showed agreement with the findings of McCaul et al. (2002) and the current study and stated that RNMB was significantly more likely to be associated with shorter operations (less than 90 minutes, 66.7\%) compared with operations lasting more than 90 minutes $(33.3 \%, \mathrm{P}=0.001)$. The agreement among these studies might refer to that fact that sufficient time is required for neostigmine to provide effective reversal, or for spontaneous recovery from neuromuscular blockade to a TOF ratio $\geq 0.90$, which may not be allowed during shorter surgery times (Miller 2011).

Despite advances in the neuromuscular monitoring methods and pharmacological agents used in anaesthesia practice, the findings of this study showed that postoperative CREs were significantly associated with RNMB ( $P=0.001)$, which was consistent with the previous studies (Grosse-Sundrup et al. 2012; Murphy et al. 2008a; Murphy et al. 2008b; Norton et al. 2013; Sauer et al. 2011) as shown in table 5. In a case-control study by Murphy et al. (2008a) to investigate whether patients who experienced postoperative CREs had a greater incidence of RNMB, they reported that, the CREs were most frequently observed in severe hypoxaemia cases (52.4\%), mild hypoxaemia (23.8\%), and upper airway obstruction (35.7\%). After appropriately matching cases with a control group who had not experienced CREs, the mean TOF ratio was found to be reduced in the control group ( $0.62 \pm 0.20$ vs. $0.98 \pm 0.07 \%, P<0.001)$. Murphy et al. (2008b) conducted another study in the same year to examined the effectiveness of quantitative (acceleromyography) and qualitative neuromuscular monitoring in reducing the incidence of RNMB after tracheal extubation. They found that RNMB (TOF ratio < 0.90 ) was more frequent in the conventional group (30\%) compared with the acceleromyography group (4.5\%; $\mathrm{P}<0.001)$. In addition, the authors revealed that mild hypoxaemia (SpO2 90-93\%) was significantly more frequent in the conventional group ( $43.3 \%$ vs. $6.7 \%)$ and severe hypoxaemia $(\mathrm{SpO} 2<90 \%)$ was also more common in the conventional group during the first 30 minutes of their PACU stay $(21.1 \%$; all $P<0.001)$. The difference between these two studies is that Murphy et al. (2008b) only looked for two types of CREs (mild and severe hypoxaemia), while in Murphy et al. (2008a), authors looked for eight types of CRE. 
However, both studies suggested that RNMB is significantly associated with hypoxaemia, which was similar to the findings of the current study.

On the other hand, both McCaul et al. (2002) and Cammu et al. (2012) showed disagreement with the findings of the two studies by Murphy et al. (2008a; 2008b) and the findings of the current study. McCaul et al. (2002) and Cammu et al. (2012) found that RNMB was not associated with hypoxaemia or upper airway obstruction during the PACU stay. In McCaul et al. (2002), this difference could possibly be attributed to the limited sample employed, using only Atracurium as an NMBD, or to the identification of RNMB as a TOF ratio $\leq 0.70$. Meanwhile, Cammu et al. (2012) used different NMBDs, such as Atracurium and Mivacurium, in addition to using a new reversal drug (called Sugammadex), which were not used in the current study or in other studies conducted by Murphy et al. (2008a; 2008b). Therefore, these differences between the present study and Murphy et al. (2008a; 2008b) on the one hand and McCaul et al. (2002) and Cammu et al. (2012) on the other might be related to the influence of different drugs on the incidence of RBMB or postoperative CREs (Miller 2011).

During the present study, the incidence of critical respiratory events in the PACU was defined according to the described criteria by Murphy et al. (2008a). Based on these criteria, the findings of this study showed that twenty patients experienced postoperative CREs during the first thirty minutes in the PACU. The CREs commonly observed most were signs of respiratory distress (50\%), mild to moderate hypoxemia (30\%), and upper airway obstruction (16.7\%). The other CREs recorded were severe hypoxemia (13.3), upper airway weakness (10\%) and inability to breathe deeply (6.7\%): as in table 6. These results of the current research are in agreement with the previous studies conducted by Xará et al. (2015), Stewart et al. (2016) and Moreno et al. (2013), who found that postoperative CREs were more frequent in patients with RNMB. Both Xará et al. (2015), Stewart et al. (2016) investigated the incidence of postoperative CREs among patients with RNMB in the PACU based on the same criteria used in the current study, which were described by Murphy et al. (2008a).

Xará et al. (2015) examined 340 patients and found that CREs happened in 67 of them (19.7\%). Postoperative CREs were more frequent in patients with RNMB $(P<.001)$. The most frequent CREs observed by Xará et al. (2015) were similar to the postoperative CREs observed in the current study, namely inability to breathe deeply (15.9\%), upper airway weakness (3.2\%) and mild-moderate hypoxemia (5.9\%). Moreover, among the 599 patients studied by Stewart et al. (2016), 97 participants experienced one or more CREs in the PACU, and these CREs were more frequent in patients with RNMB $(P=0.033)$. Types of CREs observed were also similar to the findings of this study; however, upper airway obstruction was the most frequently observed, at $78 \%$, followed by $14 \%$ who had respiratory distress, $12 \%$ with mild to moderate hypoxemia, $10 \%$ with inability to breathe deeply, $10 \%$ who had respiratory or airway muscle weakness, and 9\% who had severe hypoxemia. In addition, Stewart et al. (2016) observed some CREs that were not observed by Xará et al. (2015) or by the current study, such as pulmonary aspiration after tracheal extubation or the need for assisted ventilation. However, the differences in findings among these studies could be impacted by either the sample size or the type of patients recruited during the studies. For instance, Stewart et al. (2016) included patients undergoing open abdominal surgery who had lower 
levels of consciousness and core temperature, compared with this study, in which the median core temperature was in the normal range among patients with CREs ( 36.50 vs. $36.65, P=0.689)$ (Butterworth 2013). Hence, these factors were significantly associated with an increased risk of upper airway obstruction, which was the postoperative CREs that was most frequently observed in Stewart et al. (2016).

Elderly patients are at high risk for pulmonary aspiration resulting in impaired pharyngeal function, which is a consequence of increased incidence of misdirected swallowing (Kopman 2016). Cedborg et al. (2014) investigated the incidence of postoperative pulmonary complications caused by the presence of RNMB among elderly patients. They found that there was an intense negative effect on airway integrity with increased prevalence of pharyngeal dysfunction: from $37 \%$ in patients without RNMB to $71 \%$ during the presence of RNMB. However, in the current study and Stewart et al. (2016), there were no significant differences between the age of patients and the incidence of postoperative CREs ( $P=0.62, P=0.06$, respectively). Pedersen (1994) examined the risk factors associated with postoperative complications following general anaesthesia, and found that postoperative pulmonary complications were associated with elderly patients those aged 70 years and over. Therefore, the differences in the findings among the previous studies might be impacted by the age of their samples (Sieber and Barnett 2011). For instance, the findings reported by Cedborg et al. (2014) demonstrated disagreement with both Stewart et al. (2016) and the current study, but this might be because Cedborg et al. (2014) recruited only patients older than 65 .

The results of this study seem to suggest a significant association between BMI and postoperative CREs during the early PACU stay. BMI was significantly greater $(P=0.047)$ among patients who experienced CREs $\left(31.23 \pm 6.1 \mathrm{~kg} / \mathrm{m}^{2}\right)$ compared to those who did not $\left(26.78 \pm 3.94 \mathrm{~kg} / \mathrm{m}^{2}\right)$. According to the World Health Organisation (2016), subjects with body mass index (BMI) equal to or greater than $30 \mathrm{~kg} / \mathrm{m}^{2}$ are considered obese. Obesity has physiological effects on the respiratory system's compliance and lung volumes, which can adversely affect pulmonary gas exchange and subsequent generation of airway closure and oxygen desaturation (Hodgson et al. 2015). According to Newell et al. (2007), obese patients are more likely to develop postoperative respiratory complications. In relation to the existing literature, the effect of BMI on the oxygen saturation (SpO2) upon PACU arrival has been addressed by Cammu et al. (2012). The authors reported that BMI was significantly associated with severe hypoxemia $(\mathrm{SpO} 2<90 \%)$ during the PACU stay $(P=0.01)$.

The findings reported here can improve the current knowledge and clinical practice of perioperative management, specifically the management of NMBDs. The first step for improving NMBDs' management and postoperative outcomes is basically through following the evidence-based medical management of NMBDs, which can help to reduce complications initiated by unsuitable perioperative management. Therefore, based on the current literature and AAGBI guidelines (2016), the researcher recommends that neuromuscular monitoring in the operating theatre before extubation is required for all patients who have received NMBDs. Quantitative neuromuscular monitoring (acceleromyography) is essential to accurately assess the TOF ratio, which can help to diminish the incidence of RNMB. This will also help to prevent the 
postoperative complications associated with RNMB, and that will reduce the incidence of postoperative critical respiratory events.

there is now strong evidence to suggest that when neostigmine is used with appropriate monitoring, it can significantly decrease and possibly eliminate RNMB in the postoperative period. However, the researcher recommends that sugammadex should be used as an alternative to neostigmine for the reversal of neuromuscular blockade, as several recent studies concur that sugammadex can decrease and perhaps eliminate RNMB during the PACU stay (Brueckmann et al. 2015; Ledowski et al. 2012; Ledowski et al. 2013; Rahe-Meyer et al. 2015; Watts et al. 2012).

The current study has some limitations that need to be mentioned. The convenience sampling method and time frame sample size were applicable and appropriate for this study; however, lack of

generalizability and sampling bias are the main disadvantages of this sampling method (Polit 2014). The researcher was limited by resources and time boundaries, hence the sample employed was small, which might reduce the external validity of the findings of the current study (LoBiondo-Wood and Haber 2014). The study was carried out only on elective surgical patients in a single tertiary hospital and therefore, the results might be difficult to generalize to other surgical populations or to different settings (Greenhalgh 2014). Moreover, the present study was a prospective, observational study: no interventions were made in anaesthetic practice during the pre-operative, intra-operative or post-operative period, and all treatments were applied and managed according to the standards of the clinician who was in charge of each patient that day.

Further research into the association between the incidence of RNMB and postoperative CREs following general anaesthesia should address the limitations of this pilot study. This study suggests the need for multicentre, randomised trials in Saudi Arabia to provide better findings and more conclusive results. Enrolment of large samples is necessary for the appropriate detection of associations with the incidence of RNMB and postoperative CREs.

\section{Conclusion}

This is the first study conducted in Saudi Arabia that has investigated the association between the incidence of RNMB and postoperative critical respiratory events among patients undergoing elective surgery under general anaesthesia. This study observed evidence that the majority of patients with RNMB (TOF ratio < 0.90) experienced critical respiratory events in the PACU. In this study, the analysis demonstrated that high BMI $\left(31.23 \pm 6.1 \mathrm{~kg} / \mathrm{m}^{2}\right)$ can also contribute to critical respiratory events during the early PACU stay. Through further descriptive analysis of the sample characteristics, it was shown that female gender, shorter duration of surgery and absence of intraoperative quantitative neuromuscular monitoring were the variables that were most likely to lead to the occurrence of RNMB (TOF ratio $<0.90$ ).

In agreement with previous researches, the current study confirms the continued high incidence of RNMB upon PACU arrival during regular clinical practice, despite the use of neostigmine and qualitative TOF 
monitoring. Routine quantitative neuromuscular monitoring and optimal antagonism of the neuromuscular blockade are recommended to enhance patient safety. Therefore, these results should provoke a re-evaluation of current practice and techniques used for the monitoring and reversal of NMBDs in anaesthesia practice in Saudi Arabia. The limitations of this research, as highlighted above, along with the suggested recommendations for future practice, will provide further evidence to supplement the current research and the extant literature, which is essential in improving the quality of anaesthesia practice.

\section{Abbreviations}

\begin{tabular}{ll}
\hline Abbreviations & Definition \\
\hline PACU & Post-anaesthesia care units \\
\hline NMBDs & Neuromuscular blocking drugs \\
\hline NMBD & Neuromuscular blocking drug \\
\hline RNMB & Residual neuromuscular blockade \\
\hline TOF & Train-of-Four \\
\hline CREs & Critical respiratory events \\
\hline BMI & Body Mass Index \\
\hline ASA-PS & American Society of Anaesthesiologists Physical Status \\
\hline SpO2 & Oxygen Saturation \\
\hline RR & Respiratory Rate \\
\hline
\end{tabular}

\section{Declarations}

Ethics approval and consent to participate: obtained

Consent for publication: obtained

Availability of data and material: available

Competing interests: none

\section{Funding:}

- College of Applied Medical Sciences King Saud bin Abdulaziz University for Health Sciences,

- King Abdullah International Medical Research Center (KAIMRC), King Abdullaziz Medical City, National Guard Health Affairs, Riyadh, Saudi Arabia.

\section{Authors' contributions:}


- Faraj Alenezi, Principal Investigator: research idea, study design, data collection, data analysis, interpretation of the results, writing manuscript.

- Khalid Alnababtah: study design, ethical approvals, interpretation of the results.

- Mohammed M. Alqahtani: interpretation of the data.

- Mohammed Al Harbi: co-author: participants recruitment, data collection.

\section{Acknowledgements:}

- We would like to thank anaesthesia department, King Abdulaziz Medical City, for their cooperation during data collection.

\section{References}

Adamus, M. et al. 2008. Influence of gender on the course of neuromuscular block following a single bolus dose of cisatracurium or rocuronium. European Journal of Anaesthesiology 25(7), pp. 589-595.

Aytac, I. et al. 2016. Survey of postoperative residual curarization, acute respiratory events and approach of anesthesiologists. Brazilian Journal of Anesthesiology (English edition) 66(1), pp. 55-62.

Brueckmann, B. et al. 2015. Effects of sugammadex on incidence of postoperative residual neuromuscular blockade: a randomized, controlled study. BJA: British Journal of Anaesthesia 115(5), pp. 743-751.

Buhre, W. and Rossaint, R. 2003. Perioperative management and monitoring in anaesthesia. The Lancet 362(9398), pp. 1839-1846.

Butterworth, J. F. 2013. Morgan \& Mikhail's clinical anesthesiology. 5th ed. ed. New York: New York: McGraw-Hill.

Cammu, G. et al. 2012. A prospective, observational study comparing postoperative residual curarisation and early adverse respiratory events in patients reversed with neostigmine or sugammadex or after apparent spontaneous recovery. Anaesthesia and intensive care 40(6), p. 999.

Cedborg, H. A. I. et al. 2014. Pharyngeal Function and Breathing Pattern during Partial Neuromuscular Block in the Elderly: Effects on Airway Protection. Anesthesiology 120(2), pp. 312-325.

Claudius, C. et al. 2009. The undesirable effects of neuromuscular blocking drugs. Anaesthesia 64(s1), pp. 10-21.

Fortier, L.-P. et al. 2015. The RECITE study: a Canadian prospective, multicenter study of the incidence and severity of residual neuromuscular blockade. Anesthesia and Analgesia 121(2), pp. 366-372. 
Fuchs-Buder, T. et al. 2003. Einsatz des neuromuskulären Monitorings in Deutschland. Der Anaesthesist 52(6), pp. 522-526.

Grayling, M. and Sweeney, B. 2007. Recovery from neuromuscular blockade: a survey of practice. Anaesthesia 62(8), pp. 806-809.

Greenhalgh, T. 2014. How to read a paper : the basics of evidence-based medicine. Fifth edition. ed. Chichester, West Sussex : John Wiley \& Sons Inc.

Grosse-Sundrup, M. et al. 2012. Intermediate acting non- depolarizing neuromuscular blocking agents and risk of postoperative respiratory complications: prospective propensity score matched cohort study. British Medical Journal 345, pp. 1-14.

Herbstreit, F. et al. 2009. Impaired Upper Airway Integrity by Residual Neuromuscular Blockade Increased Airway Collapsibility and Blunted Genioglossus Muscle Activity in Response to Negative Pharyngeal Pressure. Anesthesiology 110(6), pp. 1253-1260.

Kaan, N. et al. 2012. The incidence of residual neuromuscular blockade associated with single dose of intermediate-acting neuromuscular blocking drugs. Middle East Journal of Anesthesiology 21(4), pp. 535542.

Kiekkas, P. et al. 2014. Residual neuromuscular blockade and postoperative critical respiratory events: literature review. Journal of clinical nursing 23(21-22), pp. 3025-3035.

Kopman, A. 2016. Residual Neuromuscular Blockade and Adverse Postoperative Outcomes: An Update. Curr Anesthesiol Rep 6(2), pp. 178-184.

Ledowski, T. et al. 2012. Unrestricted access to sugammadex: Impact on neuromuscular blocking agent choice, reversal practice and associated healthcare costs. 40, pp. 340-343.

Ledowski, T. et al. 2013. Introduction of sugammadex as standard reversal agent: Impact on the incidence of residual neuromuscular blockade and postoperative patient outcome. Indian Journal of Anaesthesia 57(1), pp. 46-51.

LoBiondo-Wood, G. and Haber, J. 2014. Nursing research : methods and critical appraisal for evidence based practice. 8th ed. ed. St. Louis, MO: St. Louis, MO : Elsevier Mosby.

McCaul, C. et al. 2002. Atracurium is associated with postoperative residual curarization. British Journal of Anaesthesia 89(5), pp. 766-769.

Miller, R. D. 2011. Basics of anesthesia. 6th ed Philadelphia: 6th ed.

Moreno, C. et al. 2013. Residual neuromuscular block and critical respiratory events in a post-anaesthesia care unit: 5AP2-11. European Journal of Anaesthesiology (EJA) 30, pp. 86-86. 
Murphy, G. S. 2006. Residual neuromuscular blockade: incidence, assessment, and relevance in the postoperative period. Minerva Anestesiol 72(3), pp. 97-109.

Murphy, G. S. et al. 2011. Intraoperative Acceleromyography Monitoring Reduces Symptoms of Muscle Weakness and Improves Quality of Recovery in the Early Postoperative Period. Anesthesiology 115(5), pp. 946-954.

Murphy, G. S. et al. 2013. Postoperative residual neuromuscular blockade is associated with impaired clinical recovery. Anesthesia and Analgesia 117(1), pp. 133-141.

Murphy, G. S. et al. 2015. Residual neuromuscular block in the elderly: Incidence and clinical implications. Anesthesiology 123(6), pp. 1322-1326.

Murphy, G. S. et al. 2008a. Residual neuromuscular blockade and critical respiratory events in the postanesthesia care unit. Anesthesia and Analgesia 107(1), pp. 130-137.

Murphy, G. S. et al. 2008b. Intraoperative Acceleromyographic Monitoring Reduces the Risk of Residual Meeting Abstracts and Adverse Respiratory Events in the Postanesthesia Care Unit. The Journal of the American Society of Anesthesiologists 109(3), pp. 389-398.

Naguib, M. et al. 2010. A survey of current management of neuromuscular block in the United States and Europe. Anesthesia \& Analgesia 111(1), pp. 110-119.

Nava-Ocampo, A. et al. 2002. Preferences of Mexican anesthesiologists for vecuronium, rocuronium, or other neuromuscular blocking agents: a survey. BMC anesthesiology 2(1), p. 1.

Newell, M. A. et al. 2007. Body Mass Index and Outcomes in Critically Injured Blunt Trauma Patients: Weighing the Impact. Journal of the American College of Surgeons 204(5), pp. 1056-1061.

Norton, M. et al. 2013. Residual neuromuscular block as a risk factor for critical respiratory events in the post anesthesia care unit. Revista Española de Anestesiología y Reanimación 60(4), pp. 190-196.

Pedersen, T. 1994. Complications and death following anaesthesia. A prospective study with special reference to the influence of patient-, anaesthesia-, and surgery- related risk factors. Danish Medical Bulletin 41(3), pp. 319-331.

Pietraszewski, P. and Gaszyński, T. 2013. Residual neuromuscular block in elderly patients after surgical procedures under general anaesthesia with rocuronium. Anaesthesiology Intensive Therapy 45(2), pp. 7781.

Polit, D. F. 2014. Essentials of nursing research : appraising evidence for nursing practice. 8th ed. ed. Philadelphia ; London: Philadelphia ; London : Wolters Kluwer Health/Lippincott Williams \& Wilkins. 
Rahe-Meyer, N. et al. 2015. Recovery from prolonged deep rocuronium- induced neuromuscular blockade A randomized comparison of sugammadex reversal with spontaneous recovery. Anaesthesist 64(7), pp. 506-512.

Sauer, M. et al. 2011. The influence of residual neuromuscular block on the incidence of critical respiratory events. A randomised, prospective, placebo-controlled trial. European Journal of Anaesthesiology (EJA) 28(12), pp. 842-848.

Sieber, F. E. and Barnett, S. R. 2011. Preventing postoperative complications in the elderly. Anesthesiology clinics 29(1), pp. 83-97.

Sorgenfrei, I. et al. 2005. [Does evidence lead to a change in clinical practice? Danish anaesthetists' and nurse anesthetists' clinical practice and knowledge of postoperative residual curarization]. Ugeskrift for laeger167(41), pp. 3878-3882.

Stewart, P. A. et al. 2016. The Impact of Residual Neuromuscular Blockade, Oversedation, and Hypothermia on Adverse Respiratory Events in a Postanesthetic Care Unit: A Prospective Study of Prevalence, Predictors, and Outcomes. Anesthesia \& Analgesia 123(4), pp. 859-868.

Tsai, C.-C. et al. 2008. Postoperative residual curarization: clinical observation in the post-anesthesia care unit. Chang Gung Med J 31(4), pp. 364-368.

Watts, R. W. et al. 2012. The influence of unrestricted use of sugammadex on clinical anaesthetic practice in a tertiary teaching hospital. pp. 333-339.

World Health Organization. 2016. WHO / Obesity and overweight [Online]. [Online]. Available at: http://www.who.int/mediacentre/factsheets/fs311/en/ [Accessed: 05/05/2017].

Xará, D. et al. 2015. Adverse Respiratory Events in a Post- Anesthesia Care Unit. Archivos de Bronconeumología (English Edition) 51(2), pp. 69-75.

Xue, F. S. et al. 1997. Dose- Response and Time Course of Effect of Rocuronium in Male and Female Anesthetized Patients. Anesthesia and Analgesia 85(3), pp. 667-671.

\section{Tables}

Table 1: inclusion and exclusion criteria 
Inclusion - Patients aged over 18 years.

- $\quad$ Patients who had undergone elective surgical procedures.

- Patients who received general anaesthesia only

- $\quad$ American Society of Anaesthesiologists (ASA) from 1-3

Exclusion Patients who were undergoing cardiac, thoracic or neurological surgeries, as well as patients who were undergoing abdominal emergency surgery

- $\quad$ Patients who are having history of pulmonary disease or cardiovascular comorbidities

- $\quad$ Patients undergoing elective surgery that lasted more than four hours (240 minutes)

- $\quad$ American Society of Anaesthesiologists (ASA) from 4 and 5

Table 2: Types of Critical Respiratory Events (Modified Murphy's Criteria)

1. Upper airway obstruction: if the patient required an intervention such as:

o oral airway

o jaw thrust

o nasal airway

2. Mild-moderate hypoxemia ( $\mathrm{SpO} 2$ of $93 \%-90 \%)$;

3. Severe hypoxemia $($ Spo $2<90 \%)$;

4. Signs of respiratory distress or impending ventilation failure

- accessory muscle use

o tracheal tug

- respiratory rate $>20$ breaths per minute

5. Patient could not breathe deeply while asked for by the PACU nursing staff;

6. Patient complaining of upper airway muscle weakness or symptoms of respiratory:

o difficulty swallowing: ask the patient to swallow a sip of water

o difficulty speaking

$0 \quad$ difficulty breathing

7. Patient requiring re-intubation in the PACU; and

8. Clinical evidence or suspicion of pulmonary aspiration after tracheal extubation (gastric contents observed in the oropharynx and hypoxemia). 
Table 3: Demographic Data

\begin{tabular}{|c|c|}
\hline Variables & Findings $(n=30)$ \\
\hline Age (years), median (IQR) & $35(27-53)$ \\
\hline \multicolumn{2}{|l|}{ Gender, n (\%) } \\
\hline Male & $17(56.7 \%)$ \\
\hline Female & $13(43.3 \%)$ \\
\hline \multicolumn{2}{|l|}{ ASA-PS Class, n (\%) } \\
\hline I & $10(33.3 \%)$ \\
\hline ॥ & $17(56.7 \%)$ \\
\hline III & $3(10 \%)$ \\
\hline $\mathrm{BMI}(\mathrm{kg} / \mathrm{m} 2)$, mean $\pm \mathrm{SD}$ & $29.45 \pm 5.56$ \\
\hline \multicolumn{2}{|l|}{ Type of surgery, n (\%) } \\
\hline General & $13(43.3 \%)$ \\
\hline Urology & $4(13.3 \%)$ \\
\hline ENT & $10(33.3 \%)$ \\
\hline Plastic & $2(6.7 \%)$ \\
\hline OB/GYN & $1(3.3 \%)$ \\
\hline \multicolumn{2}{|l|}{ NMBD used, n (\%) } \\
\hline Succinylcholine & $1(3.3 \%)$ \\
\hline Rocuronium & $26(86.7 \%)$ \\
\hline Cisatracurium & $3(10 \%)$ \\
\hline \multicolumn{2}{|l|}{ Reversal used, n (\%) } \\
\hline None & $7(23.3 \%)$ \\
\hline Neostigmine & $23(76.7 \%)$ \\
\hline
\end{tabular}

Key: $\mathrm{n}(\%)=$ number (percentage); IQR= Interquartile Range; $\pm \mathrm{SD}= \pm$ standard deviation; ASA-PS Class= American Society of Anaesthesiologists Physical Status class; BMI= Body Mass Index; kg/m2= Kilogram per meter square ENT= Ear, Nose and Throat; OB/GYN= Obstetrics and Gynaecology; NMBD = neuromuscular blocking drug. 
Variables

Age, $n(\%)$
$18-50$ vs. $\geq 51$ years

Gender, $\mathrm{n}(\%)$

Male/Female

ASA-PS Class, $n(\%)$

I

II

III

BMI $(\mathrm{kg} / \mathrm{m} 2)$, mean $\pm \mathrm{SD}$

Neuromuscular monitoring before extubation, $\mathrm{n}(\%)$

Yes/No

Duration of the surgery,

$<90$ min vs. $\geq 90 \mathrm{~min}$

$\mathrm{SpO}_{2}$, upon arrival in the PACU, median (IQR)

$\mathrm{RR}$ (breaths/min), upon arrival in the PACU, median (IQR)
RNMB

(TOF ratio <0.90),

$n=16$

$11(50 \%)$ vs. 5

$(62.5 \%)$

$6(35.3 \%) / 10(76.9 \%)$

7(43.8\%)

9(56.3\%)

$0(0.0 \%)$

$30.82 \pm 5.29$
$11(64.7 \%) /$

$3(23.1 \%)$

$11(50 \%)$ vs. 3

$(37.5 \%)$

0.0544

$3(21.4 \%)$

$8(57.1 \%)$

$3(21.4 \%)$

$28.53 \pm 6.41$
0.033

0.103

0.294

$\mathrm{P}$
value 
Table 5: Comparison between the variables with presence or absence of CREs upon arrival in the PACU.

\begin{tabular}{llll} 
Variables & \multicolumn{1}{c}{ CRE (n=20) } & \multicolumn{1}{c}{$\begin{array}{c}\text { No CREs } \\
(\mathbf{n = 1 0})\end{array}$} & $\begin{array}{l}\text { P } \\
\text { value }\end{array}$ \\
\hline Age (years), median (IQR) & $35(27-51)$ & $35(30-53)$ & 0.62 \\
BMI (kg/m2), mean \pm SD & $31.23 \pm 6.17$ & $26.78 \pm 3.94$ & 0.047 \\
Duration of surgery (min), median (IQR) & $82(75-161)$ & $106(86-158)$ & 0.403 \\
Temperature (C'), median (IQR) & $36.50(36.40-$ & $36.65(36.40-36.90)$ & 0.689 \\
$\begin{array}{l}\text { TOF ratio upon arrival in the PACU, median } \\
\text { (IQR) }\end{array}$ & $36.80)$ & $0.96(0.91-1.00)$ & 0.001 \\
Incidence of RNMB & $0.88(0.72-0.89)$ & & \\
(TOF ratio <0.90), $\mathrm{n}(\%)$ & & $1(10 \%)$ & 0.001
\end{tabular}

Key: $\mathrm{n}(\%)=$ number (percentage); IQR = Interquartile Range; $\pm \mathrm{SD}= \pm$ Standard Deviation; CREs= Critical Respiratory Events; $\mathrm{BMI}=$ Body Mass Index; $\mathrm{kg} / \mathrm{m} 2=$ Kilogram per meter square; $\mathrm{min}$ = minutes; $\mathrm{TOF}=$ Train-of-Four; PACU= Post-Anaesthesia Care Unit; RNMB= Residual Neuromuscular Blockade.

Table 6: Incidence of CREs in the PACU

\begin{tabular}{ll} 
Variable & Incidence \\
\hline Upper airway obstruction & $5(16.7 \%)$ \\
Mild-moderate hypoxemia & $9(30 \%)$ \\
Severe hypoxemia & $4(13.3 \%)$ \\
Signs of respiratory distress & $15(50 \%)$ \\
Inability to breathe deeply & $2(6.7 \%)$ \\
Upper airway weakness & $3(10 \%)$
\end{tabular}

\section{Figures}




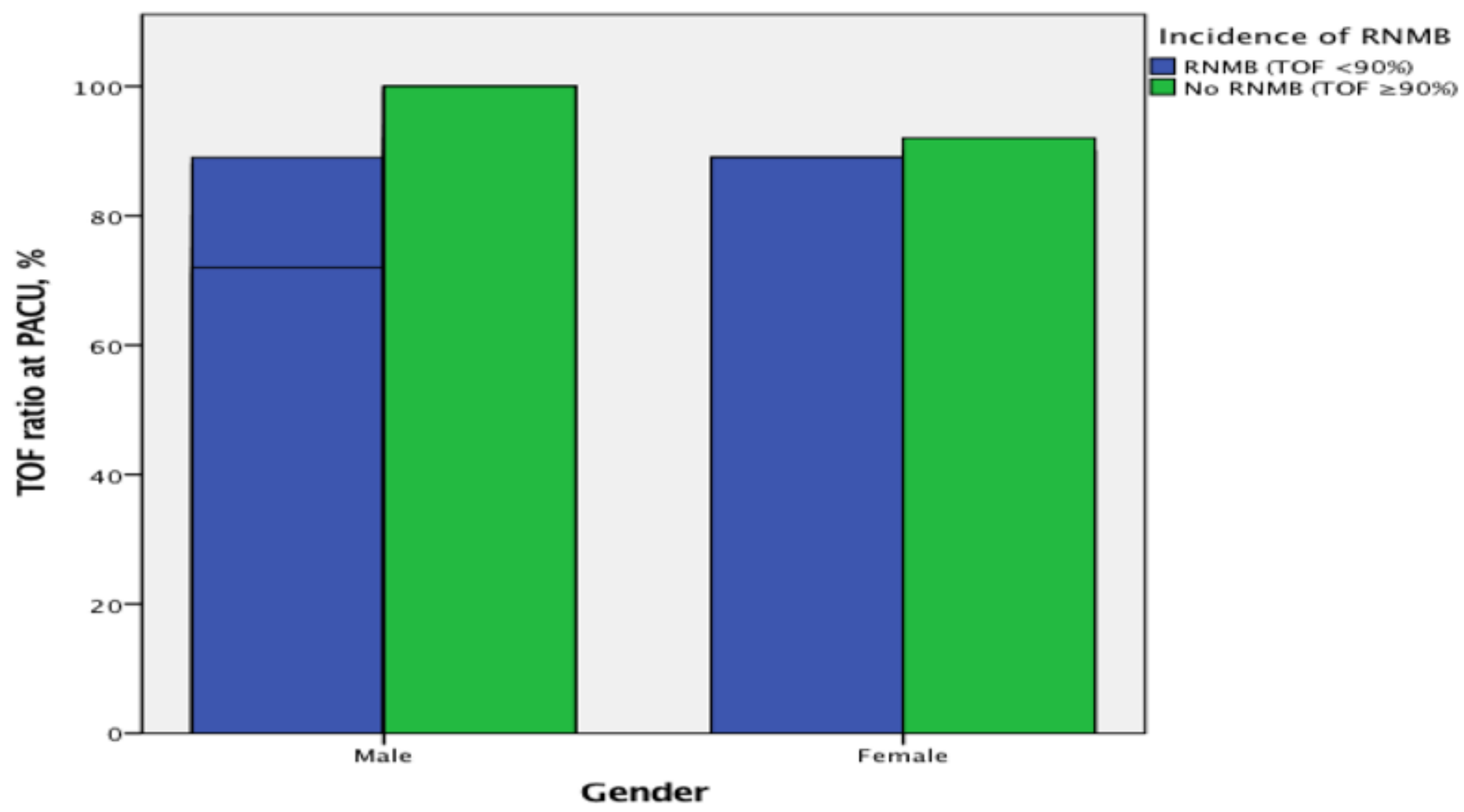

Figure 1

The incidence of RNMB among the sample based on their gender 